Article

\title{
Evaluating Mine Design Alternatives for Social Risks Using Discrete Choice Analysis
}

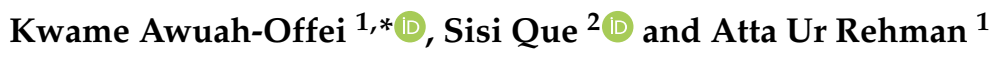 \\ 1 Thomas J. O'Keefe Institute for Sustainable Supply of Strategic Minerals, Missouri University of Science \& \\ Technology, Rolla, MO 65409, USA; atta@mst.edu \\ 2 Key Laboratory of Hydraulic and Waterway Engineering of the Ministry of Education, College of River and \\ Ocean Engineering, Chongqing Jiaotong University, Chongqing 400074, China; sisique@126.com \\ * Correspondence: kwamea@mst.edu
}

check for updates

Citation: Awuah-Offei, K.; Que, S.; Ur Rehman, A. Evaluating Mine Design Alternatives for Social Risks Using Discrete Choice Analysis. Sustainability 2021, 13, 8700. https:// doi.org/10.3390/su13168700

Academic Editor: Glen Corder

Received: 29 June 2021

Accepted: 28 July 2021

Published: 4 August 2021

Publisher's Note: MDPI stays neutral with regard to jurisdictional claims in published maps and institutional affiliations.

Copyright: (c) 2021 by the authors. Licensee MDPI, Basel, Switzerland. This article is an open access article distributed under the terms and conditions of the Creative Commons Attribution (CC BY) license (https:// creativecommons.org/licenses/by/ $4.0 /)$.

\begin{abstract}
As with other engineering design tasks, mine design involves setting design objectives and constraints (the feasible solution space) and finding the optimal design alternative. Mine engineers often struggle to incorporate the preferences of local community members into their evaluation of mine design alternatives because the mining literature lacks tools to quantify such risks during mine planning. This paper presents an approach to evaluate community acceptance (i.e., community preferences for the alternatives) using discrete choice models and decision-based design during mine planning. Using discrete choice models and a rigorous framework, engineers can estimate the cost of social risks as a function of the probability that individuals in the host community will prefer a particular design alternative. They can then estimate the overall utility of a particular design alternative to the project proponents. This paper illustrates the proposed approach with a strategic mine planning exercise for a gold mine. The framework can be a useful tool for designing mines for sustainability, if combined with effective community engagement and management's commitment to creating shared value.
\end{abstract}

Keywords: mine planning; design for sustainability; mining; social risk; social license to operate

\section{Introduction}

Engineering design is a process that includes: (i) establishing design objectives and specifications; (ii) determining measures of performance; (iii) generating design alternatives; (iv) evaluating and testing alternatives; (v) selecting the optimal alternative; and (vi) implementing the best design. Mine planning and design, which is the process of devising a plan for developing a mineral deposit (i.e., preparing the land for extraction), extracting the deposit, and reclaiming and closing the mine, follows a similar process. The nature and objectives of mine planning and design vary depending on the scope (strategic versus tactical) [1]. Generally though, the objectives can be categorized into economic (e.g., maximizing returns, reducing costs, etc.), safety (e.g., ensuring safe equipment interaction, ensuring stable openings and slopes, etc.), and sustainability objectives (to the extent that one can separate worker safety and health from broader sustainability goals, e.g., reducing biodiversity impacts, reducing emissions to air and water, reducing poverty in the host community, etc.) [2].

While mining engineers have many tools for evaluating economic [3] and safety [4] objectives, there are not as many tools for evaluating sustainability considerations in mine planning and design [5-7]. Yet, especially in long range mine planning, there are many decisions that have significant sustainability implications and impact the social risks associated with mineral projects. (We define social risks here to mean "the range of potential impacts on a project that may result from its interaction with communities and stakeholders", per Barclay et al. [8]. We note that Kemp et al. [9] call this type of risk "business risk" to differentiate it from risk to communities. For our purposes, we choose 
to call it "social risk" to differentiate this risk from other risks to the mining project.) As evidenced by recent large projects (e.g. Pascua Lama and Bristol Bay) that have been halted or significantly altered because of community concerns over how the mine plan will impact the environment and ecological services, the sustainability considerations carry significant implications for project success. Thus, the ability of mining companies and mine engineers to adequately address sustainability in design hinges on the availability of rigorous tools that facilitate sustainability considerations in addition to other efforts (e.g., making mine planning teams more inter-disciplinary so that they are better able to identify and quantify social risks).

In the last few decades, ideas regarding how we incorporate environmental aspects into design have evolved into eco-design and, ultimately, to the concept of design for sustainability (DfS). DfS is more comprehensive and far reaching in its aspirations to reimagine how to satisfy the need while considering long term sustainability impacts. For mining to contribute to sustainable development, the industry will have to adopt more DfS approaches and principles in the way it does business. This is even more important given the material intensity of the green energy transition [10].

Rocha, Antunes, and Partidário [11] describe a DfS hierarchy that moves from higher level strategic activities to tactical and to operational activities with narrower scopes. The mining industry would have to engage in DfS at all these levels to align its business practices with sustainable development goals. Mine planning and design fits into the operational level as it involves designing how a company goes about extracting resources. Nonetheless, it is still important for the industry to conduct mine planning and design with sustainability in mind. To fit into the DfS paradigm, mining engineers need rigorous tools to evaluate the social and environmental aspects of the design.

A key element of accounting for sustainability in mine planning and design is incorporating the preferences of individuals in host communities and other stakeholders. This has been formalized into concepts such as free, prior, and informed consent [12-14], social license to operate [15,16], and legitimacy [16-18]. Yet, the literature lacks formal frameworks for design engineers to incorporate the preferences of host communities into their design. The few examples that exist (e.g., [5]) are based on multi-criteria decision analysis tools that rank alternatives based on subjective weights $[19,20]$. Thus, in many cases, engineers design the mine without due regard to community preferences and the companies try to "sell" the "optimal" design to the community and other stakeholders leading to conflict and delays in mine permitting. In this paper, we argue that just as decision-based design [21] has been used to formally incorporate customer demand into product design [22], it can be used, in combination with discrete choice analysis, to incorporate community acceptance (preferences) in long range mine planning and design. When done well, the decision-based design approach should avoid subjective weights and, thus, overcome the weakness of multi-criteria decision analysis approaches. This paper, therefore, seeks to present a framework based on decision-based design and discrete choice analysis for incorporating local community acceptance into mine planning and design. We focus on long range mine planning and design because that is the stage where mining engineers make strategic decisions with significant impact on sustainability [1].

\section{Methodology}

\subsection{Decision-Based Design Framework}

Broadly speaking, engineering design decision frameworks are either based on objective or bounded rationality $[23,24]$. While frameworks based on objective rationality, such as decision-based design, have known limitations [23], they are simple and able to provide formal models that are useful for design and research. Hazelrigg [21] proposed decision-based design (DBD) as a framework for engineering design that allows design engineers to incorporate demand, cost, and profit into design decisions and maximize the utility to the company making the products. Wassenaar et al. [22] later revised this 
framework to include the use of discrete choice analysis to elicit customer preferences and estimate product demand (Figure 1).

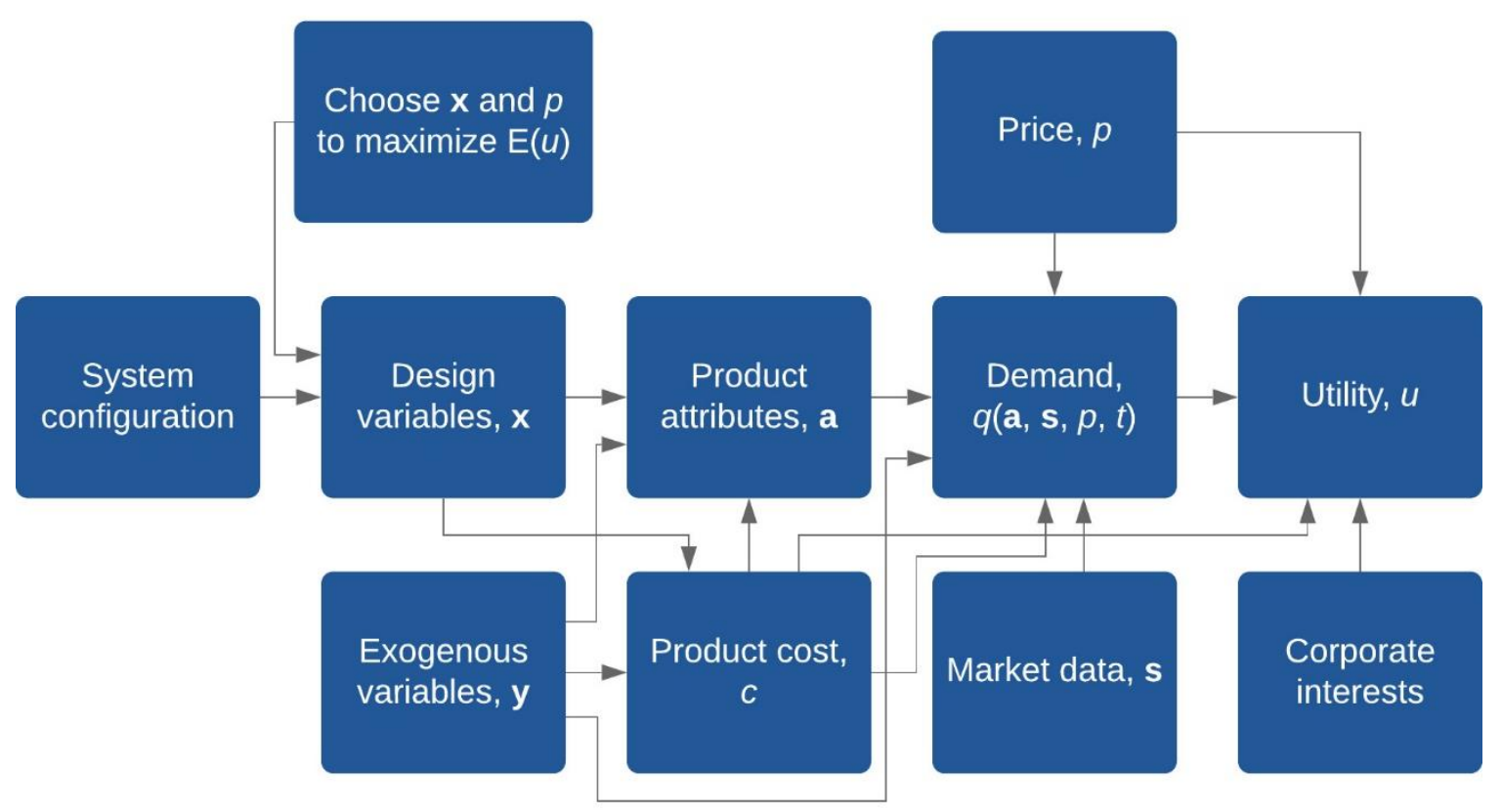

Figure 1. Decision-based design framework (adapted from [21,22]).

DBD frames product design as a utility maximizing exercise where engineers choose the design (decision) variables, $\mathbf{x}$, that maximizes the expected utility, $E(u)$. While the design variables affect customers' choices, they are not necessarily the same as the product attributes, $\mathbf{a}$, that customers use to make their choice decisions. The product attributes also depend on exogenous variables, $\mathbf{y}$, and product cost, $c$. The product cost, $c$, also depends on $\mathbf{x}$ and $\mathbf{y}$. The utility, $u$, is a function of demand, cost, price, and corporate preferences. Because this is a decision made under uncertainty, the utility function should capture this uncertainty (by, e.g., using the expected utility [22]).

In Hazelrigg's original framework [21], the demand, $q$, is a function of product attributes, a, time, $t$, and price, $p$. Wassenaar et al. [22] introduced the idea of using discrete choice analysis to elicit customer preferences and use the discrete choice model to predict demand as a function of product attributes, socio-economic and demographic data on consumers, price, and time. Discrete choice analysis has long been used to understand consumer preferences in market research [25] and is superior to models that use group averages to describe demand from consumers with different socio-economic and demographic attributes [22].

\subsection{Proposed Framework}

Figure 2 shows our proposed framework for incorporating the preferences of host community members into mine planning and design decisions. Our approach is based on decision-based design [26] and discrete choice analysis [27], similar to Wassenaar's approach [22]. As with other engineering design tasks, mining engineers during long range mine planning and design have design variables, $\mathbf{x}$, that the engineer has control over (e.g., where to place mine roads, whether to build a mine camp or bus workers in from nearby towns etc.) and these design variables manifest as attributes of the mine, $\mathbf{a}$, that influence stakeholder/community preferences. Similarly, there are exogenous variables, $\mathbf{y}$, outside the control of the engineer (e.g., labor costs, cost of capital, mine safety regulations, etc.) and corporate interests of mining companies that affect the expected utility. 


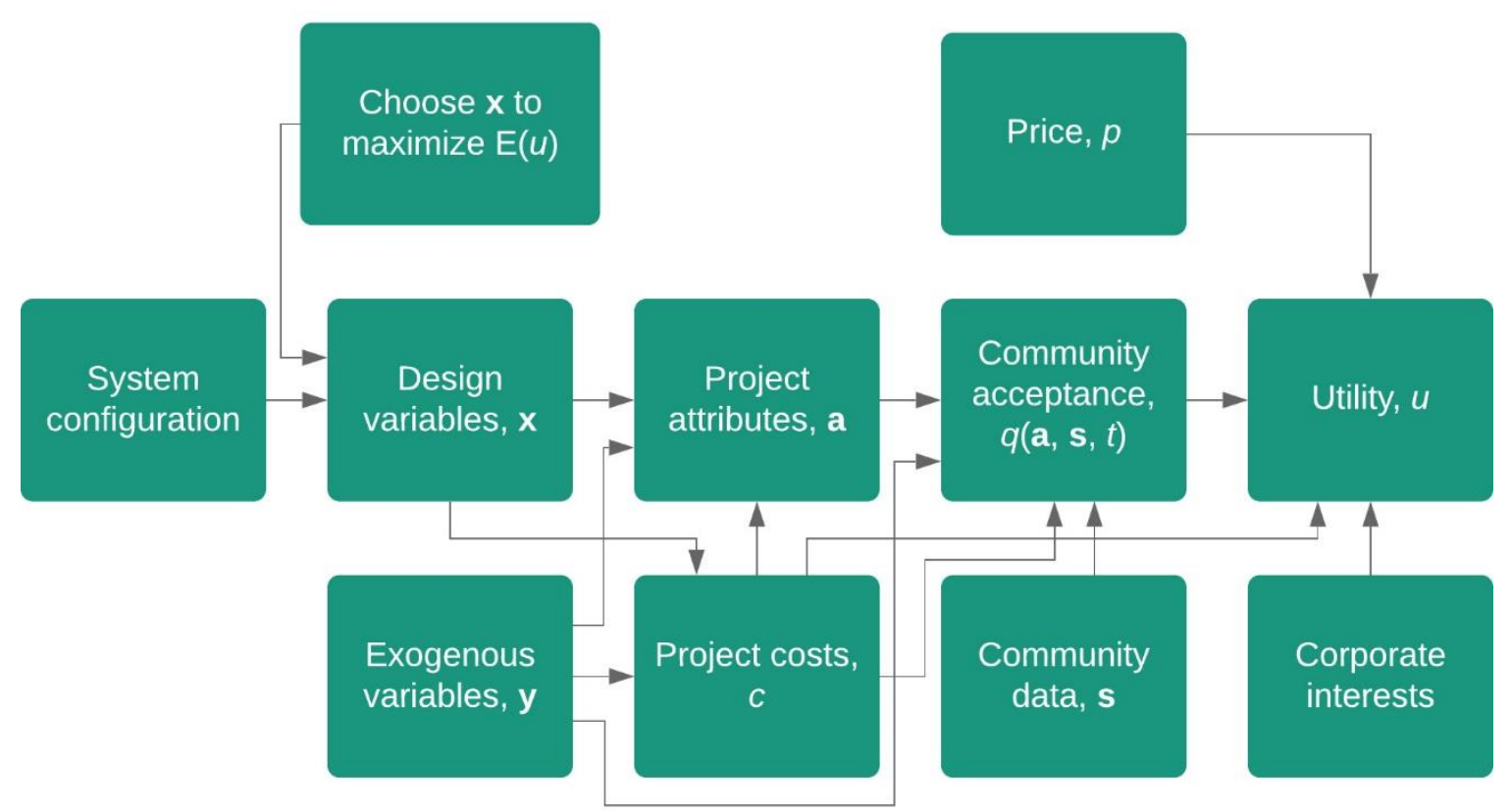

Figure 2. Framework for incorporating community preferences into mine planning and design.

Table 1 compares conventional DBD to our proposed framework. There are several important distinctions because conventional DBD addresses how to incorporate customer demand into design decisions whereas our framework addresses how to incorporate the local community preferences into design decisions to mitigate social risks. The unique aspects of our framework and problem are discussed in the following sections.

Table 1. Conceptual comparison of conventional DBD and proposed framework.

\begin{tabular}{|c|c|c|}
\hline Dimension & DBD & Proposed Framework \\
\hline Design o & Product to be sold to customers & Mine to be built in host community \\
\hline Demand & Demand for product & Community acceptance \\
\hline Price & Price at which consumers buy the product & $\begin{array}{l}\text { Because community acceptance is not a formal } \\
\text { transaction, "price" is less obvious }\end{array}$ \\
\hline Cost & Cost to manufacture the product and other life cycle costs & Capital and operating costs of the mine \\
\hline Utility & $\begin{array}{l}\text { Utility under uncertainty typically reflecting profit } \\
\text { accruing to the manufacturer }\end{array}$ & $\begin{array}{l}\text { Utility under uncertainty reflecting value of } \\
\text { developing the mine that accounts for social risks }\end{array}$ \\
\hline
\end{tabular}

\subsubsection{Demand vs Community Preferences}

Conventional decision-based design accounts for customer demand for the product in the design decisions. Since the goal of our framework is to incorporate community members' preferences in long range mine planning and design, we propose an estimate of the level of acceptance (while this might be similar to the levels of social license to operate (SLO) articulated by Thomson and Boutilier [15], we choose not to pose it as a measure of SLO because of the noted deficiencies in measuring SLO [16].) for a particular design option instead. Similar to customer demand, we can only provide a good estimate of the level of "acceptance" for a particular design option under uncertainty during the design stage.

We propose to use discrete choice analysis to model individual preferences, similar to Wassenaar et al. [22]. Many researchers have used discrete choice analysis to understand individual preferences for mineral projects [28-30]. Our previous research proposed a three-stage process for discrete choice analysis for mining community engagement [30] and a means to validate choice experiments in mining to ensure they are valid [31]. 
Discrete choice theory postulates that individual $n$ 's utility, $u_{n i}^{\prime}$, for alternative $i$ in the choice set can be separated into the component that can be explained by observed variables, $\mathbf{v}_{n i}$, and a random component, $\varepsilon_{n i}$ (Equation (1)). The observable variables, in this case, would be the attributes of a mineral project alternative $i, \mathbf{a}_{i}$, and the demographic (socio-economic) data, $\mathbf{s}_{n}$, of the individual (i.e., $\mathbf{v}_{n i}=\left[\mathbf{a}_{i} ; \mathbf{s}_{n}\right]$ ). Here, our model differs from Wassenaar et al. [22] because they include the price of the product in the observable variables whereas we do not (see Section 3.2 for discussion on the role of price).

$$
u_{n i}^{\prime}=\mathbf{v}_{n i}+\varepsilon_{n i}
$$

The list of mineral project attributes and demographic factors that constitute $\mathbf{v}_{n i}$ depends on the project or context. However, our previous research has developed a list of 16 project attributes and five demographic factors (age, education, income, number of children, and gender) that appear to be robust across international boundaries, which can serve as a starting point [32]. In that work, we used a literature review to identify factors that might affect decisions to support a mine and asked respondents from the United States, Turkey, and China to rank the importance of each factor in their decision to support a mine proposed in their community. Respondents also had a chance to add additional factors.

There are various discrete choice models that one can use to model individual preferences based on the results of a valid discrete choice experiment (a survey that repeatedly asks individuals to indicate their preferred alternative among a set of alternatives). Different models have different strengths and weaknesses depending on the application [33]. Regardless of the model, Equation (2) shows the probability that an individual, $n$, with specific demographic attributes, $\mathbf{s}_{n}$, chooses alternative $i$. Using a discrete choice model and Equation (2), we propose then that mine engineers can estimate the level of community acceptance for each design alternative just as Wassenaar et al. [22] proposed using discrete choice analysis to estimate the demand for each product alternative. We illustrate this later in Section 3.

$$
\operatorname{Prob}_{n}(i)=\frac{\exp \left(\mathbf{v}_{n i}\right)}{\sum_{\forall i} \exp \left(\mathbf{v}_{n i}\right)}
$$

\subsubsection{Price}

The utility function in conventional DBD includes the price of the product. Individuals in the host community do not "buy" the product of the design exercise in a transaction. However, they "pay a price" when they live near the mine and live with the consequences of the mine such as increased noise levels, traffic, and potential impacts on the environment $[28,34]$. Because we are proposing that these impacts (noise, air emissions, water impacts, etc.) be included in the project attributes for discrete choice analysis, we see no reason to specifically include a "price" term in the discrete choice model (the equivalent of the "demand" function in Wassenaar et al.'s model). Consequently, our framework does not include a price term in the community acceptance function.

We also distinguish the price of the mine's product (gold, copper, zinc etc. price) from the price "paid" by the community members. Because the community members are not "buying" the mine's product but the willingness to live near the mine, the commodity price is not the appropriate term to include in the community acceptance model. However, the commodity prices impact the utility to the mining company and should therefore be captured in the utility function for the design. This is discussed further in Section 2.2.4.

One difference, even when discussing commodity prices, between our framework and conventional DBD is that most mines are price takers and do not set commodity prices. Hence, our framework removes the price setting step in conventional DBD. We acknowledge that there are situations where mines set commodity prices because of the market for the commodity. In such a case, just as in conventional DBD, the design task changes to "choose the price and design variables, $\mathbf{x}$, to maximize the expected utility". We believe our framework will still work and there is no significant drawback. 


\subsubsection{Cost}

As with conventional DBD, each mine design alternative comes with associated capital and operating costs. Mine engineers already include these costs in design tools. For example, capital and operating costs are included in mine sequence optimization algorithms to determine the optimal net present value (NPV) [5]. Therefore, cost (capital and operating) is part of the utility function for the mining company. Moreover, community acceptance affects both capital and operating costs just as demand affects product cost in conventional DBD. For example, community discontent can lead to protests that result in delays to project construction with significant cost implications. Davis and Franks [35] estimate that, for an exploration project, delays can cost about $\$ 10,000$ per day. A key part of our framework is internalizing this cost (cost associated with social risk/discontent) in the project. We propose that the social risk cost, $c_{s r}$, should be treated as an additional operating cost item. While the exact functional form of the social risk cost would necessarily vary from one project to the other, the function should: (1) vary with the scale of production (i.e., it is not a fixed cost regardless of the annual production estimates) and the level of community acceptance (i.e., $c_{s r}=f\left(\operatorname{Prob}_{n}(i)\right.$, scale of production) $)$ associated with each alternative; and (2) $\frac{d c_{s r}}{d \mathbf{P r o b}_{n}(i)}<0$. One way to address the variation with the scale of production is to model the social risk cost as a unit cost that varies with the scale of production. Regardless of how one addresses the social risk cost function, the key to this approach is to fit a function that represents the relationship between level of community acceptance and the associated social risk cost. This can be done based on empirical data from multiple mining projects and incidents in similar circumstances.

\subsubsection{Utility}

The utility function in our framework plays a similar role as in conventional DBD. In each case, the utility function describes what drives the design decision. In Hazelrigg's original framework [21] this is a von Neumann-Morgenstern utility that captures the profit from selling the products to customers. Wassenaar et al. [22] used the expected utility to capture the utility under uncertainty. The utility in our framework is similar as there is uncertainty in estimating the utility giving the many gaps in our knowledge of things such as cost, commodity prices, and community acceptance. In our framework, the utility should reflect the economic value accruing to the mining company from developing the mine after accounting for social risk costs. This is the main reason for incorporating community preferences into the design decision. The hypothesis is that a decision mechanism that captures community preferences as a function of the real or perceived ecological, economic, and social impacts will lead to sustainable outcomes. Thus, this utility captures sustainability explicitly.

\section{Case Study}

To illustrate our approach, we use a case study of the strategic mine planning of a gold deposit (Figure 3). Table 2 shows the base case input parameters used in the strategic mine planning exercise conducted in GEOVIA Whittle. The case study is an open pit mine, which we assume will be mined with conventional truck and shovel mining, heap leaching of the crushed ore followed by carbon in column (CIC) processing to recover gold. We used Whittle to determine the optimal pit outline using the pseudoflow algorithm [36] and evaluate various scheduling options (Figure 3). We created design alternatives using initial capital, mining production rates, processing throughputs, and annual production costs (which are a function of the unit cost and annual production) as the design variables. Table 3 shows these design variables. These design variables were correlated with project attributes that influence individual preferences. We used all 16 project attributes that we found to be relevant in our previous work [29]. However, the 10 alternatives we evaluated in this work vary only in the number of employees (job opportunities) and mine life (Table 3). All other attributes from our previous work are deemed to remain the same for these alternatives. 


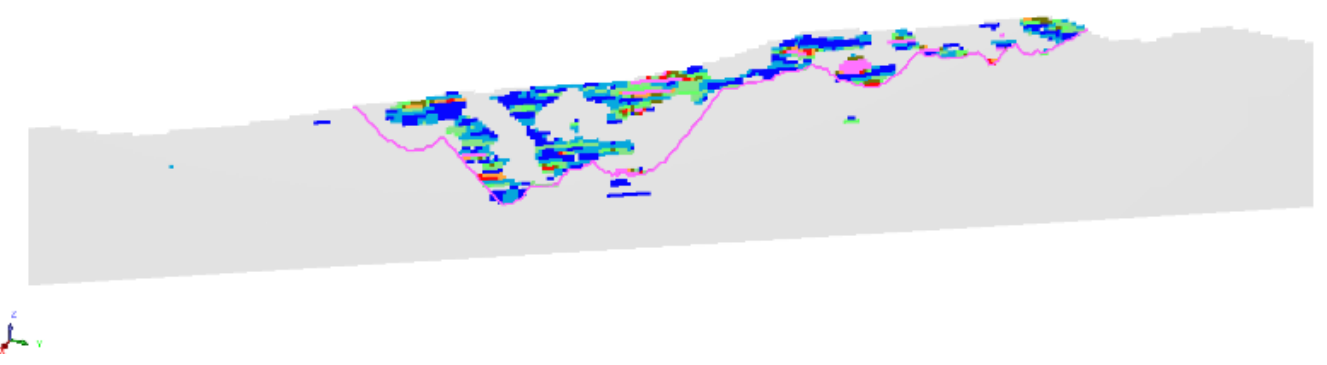

Figure 3. Geologic cross-section of case study deposit showing optimal pit outline. Colors show gold grades increasing as colors change from blue to red. Gray shows material with no gold mineralization.

Table 2. Input data for mine planning and design.

\begin{tabular}{cc}
\hline Item & Input Value \\
\hline Overall pit slopes & $55^{\circ}$ \\
Unit mining cost & $\$ 3.28 / \mathrm{t}$ \\
Unit processing cost & $\$ 19.25 / \mathrm{t}$ \\
Processing recovery & $82 \%$ \\
Gold price & $\$ 1500 / \mathrm{oz}$. \\
Reclamation costs & $\$ 3$ million \\
\hline
\end{tabular}

Table 3. Case study design alternatives.

\begin{tabular}{|c|c|c|c|c|c|}
\hline Alternative & Capital Cost (\$) & $\begin{array}{l}\text { Production Rate }{ }^{1} \\
\text { (Tonnes) }\end{array}$ & $\begin{array}{l}\text { Processing Throughput } \\
\text { (Tonnes) }\end{array}$ & $\begin{array}{l}\text { Mine Life } \\
\quad(y r s)\end{array}$ & $\begin{array}{l}\text { No. of People } \\
\text { Employed }\end{array}$ \\
\hline 1 & $600,000,000$ & $15,000,000$ & $9,000,000$ & 34 & 390 \\
\hline 2 & $650,000,000$ & $16,000,000$ & $9,600,000$ & 32 & 420 \\
\hline 3 & $700,000,000$ & $17,000,000$ & $10,200,000$ & 34 & 450 \\
\hline 4 & $750,000,000$ & $18,000,000$ & $10,800,000$ & 29 & 480 \\
\hline 5 & $800,000,000$ & $19,000,000$ & $11,400,000$ & 27 & 510 \\
\hline 6 & $850,000,000$ & $16,000,000$, & $9,600,000$ & 32 & 300 \\
\hline 7 & $900,000,000$ & $17,500,000$ & $10,500,000$ & 30 & 276 \\
\hline 8 & $950,000,000$ & $19,000,000$ & $11,400,000$ & 27 & 264 \\
\hline 9 & $1,000,000,000$ & $21,500,000$ & $12,900,000$ & 24 & 252 \\
\hline 10 & $1,500,000,000$ & $23,000,000$ & $13,800,000$ & 23 & 240 \\
\hline
\end{tabular}

${ }^{1}$ Production rate and throughputs were ramped up over the first four years to the values shown here. Year 1 was $50 \%$, Year 2 was $66 \%$, and Year 3 was $80 \%$ of the values shown here. The production rate and throughput then remained the same for the rest the mine life.

We wrote a MATLAB code with the following pseudo code to simulate the case study and estimate the utility.

1. READ input data

2. FOR number of replications

a Sample demographic characteristics

b Estimate $\operatorname{Prob}_{n}(i)$ for each individual $n$ and alternative $i$ (Equation (2))

c Determine unit social risk cost using Equation (3)

3. Estimate average unit social risk cost

4. Estimate present value of total social risk cost

After generating the design alternatives in Whittle, we extracted the data from Whittle and used them as input into our MATLAB code to estimate the utility after accounting for social risk costs. The key steps of the process are explained in the following subsections. For this case study, we run 1000 replications to examine the uncertainty. 


\subsection{Community Preferences}

We used a conditional logit model (a discrete choice model) of a mining project similar to the one in this case study, from our previous work [29], to model individual preferences for the alternatives. Table 4 shows the coefficients for all variables in the model, which was for the mining community of Salt Lake City, Utah, USA. We used Equation (2) to estimate the probability that each simulated individual in the community will choose each of the 10 alternatives. We simulated 50,000 residents using the same demographic distributions for St. Lake City, UT, USA, for age, gender, education, and income as we previously reported [29]. We used Monte Carlo simulation to sample from the demographic distributions.

Table 4. Coefficients of conditional logit model [29].

\begin{tabular}{cc}
\hline Variable & Coefficient \\
\hline Demographic attributes & \\
Age & 0.01 \\
Gender & -0.02 \\
Household income & 0.0043 \\
Education & 0.0013 \\
Project attributes & \\
Job opportunities & 1.1259 \\
Income increase (for all local residents) & 0.66 \\
Increase in housing costs & -1.0416 \\
Labor shortage for other businesses & -0.0924 \\
Noise pollution & -0.958 \\
Water pollution & -0.1956 \\
Air pollution & -1.0952 \\
Land pollution & -0.2485 \\
Population increase & -0.0709 \\
Infrastructure improvement & 0.6527 \\
Crime increase & -1.1753 \\
Traffic increase & -0.1938 \\
Permit approval decision making mechanism & 0.1634 \\
Availability of independent and transparent information & 0.846 \\
Mine buffer & 0.6684 \\
Mine life & 0.1181 \\
\hline
\end{tabular}

\subsection{Cost}

Our optimization model in Whittle already contains mining and processing costs using the unit costs in Table 2. We modeled the social risks as additional cost that depends on the average probability of residents choosing that alternative. The relationship between the probability of acceptance and social risk cost depends on the project and will require empirical data to fit an accurate curve. In this case study, we use a unit cost per tonne approach to account for scale of production. A quadratic function (e.g., Equation (3)) with a stochastic term, $\varepsilon$, can adequately express such a relationship between the probability of acceptance and the unit cost (per tonne of mining) of social risk, $c_{1}$. For this particular case study, we used $a=0.5, b=-1$, and $c=05$ (Figure 4 ) and a normal distribution with mean of zero and standard deviation of 0.1 for the stochastic term. We used this primarily for illustration, but this function meets all the properties defined in Section 2.2.3.

$$
c_{1}=a+b \operatorname{Prob}_{n}(i)+c\left(\operatorname{Prob}_{n}(i)\right)^{2}+\varepsilon
$$

\subsection{Utility}

The utility function depends on the company's preferences and how they value the various benefits and costs. We use the expected net present value (NPV) of cash flows as the utility as the NPV is a common metric for evaluating mine planning and design alternatives. 
We use the discounted cash flows from our Whittle optimization work, combined with the discounted social risk costs from the Monte Carlo simulation to estimate the NPV.

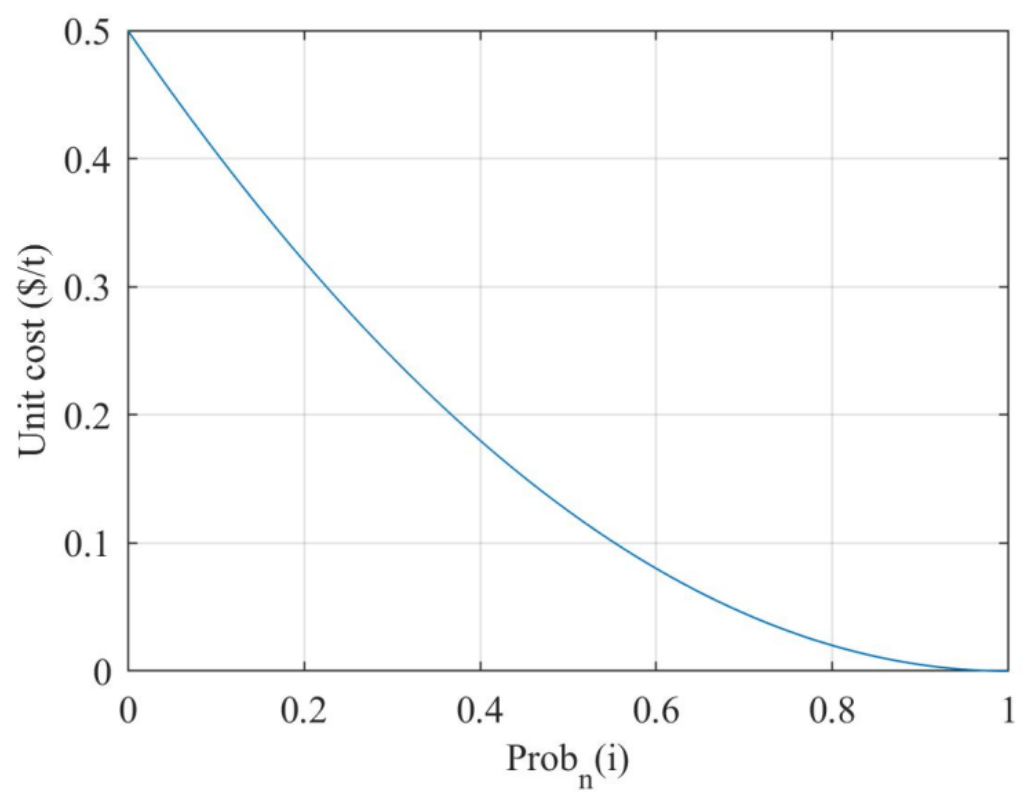

Figure 4. Unit cost of social risk for the case study deposit.

\subsection{Uncertainty Characterization}

We use Monte Carlo simulation to characterize uncertainty in our case study. While there are several stochastic variables in this problem, we chose to focus only on the uncertainty in the estimate of the cost associated with social risk because: (1) the literature contains many examples of work related to characterizing uncertainty in mine planning and design; (2) accounting for the social risk and uncertainty is the main focus of this work; and (3) we believe there is no loss of generality as one can easily use Monte Carlo simulation to account for uncertainty due to other variables once their distributions are known.

In this case study, the main sources of uncertainty are the demographics of the simulated population and its effect on the probability of accepting the design alternatives, and the uncertainty in the unit cost (Equation (3)). In the case of the demographics, we sample the population demographics from the cumulative density functions constructed from the distributions of age, gender, education, and income. For the unit cost, we account for uncertainty by sampling for the stochastic term, $\varepsilon$, from the normal distribution.

\subsection{Results}

Figures 5-7 and Table 5 show the results of the case study. The Appendix A also shows the optimal production sequence for all alternatives from Whittle. Figure 5 shows the distribution of unit costs for Alternative 1, as an example. As one would expect, given that we assumed the stochastic term is normally distributed, the distribution is symmetric. We observe similar trends for the other alternatives.

Figure 6 shows the social risk cost per tonne of mining from the simulation as box plots. When that cost is applied to the total amount of material mined each year and discounted, we obtain the total present value of cost associated with the social risk for each alternative (Figure 7). That overall cost ranges from $\$ 36.4$ to $\$ 45.5$ million for this case study. Table 5 shows the expected NPV for each alternative after accounting for the social risk costs in the evaluation. The overall NPVs range from $\$ 3.553$ to $\$ 4.256$ billion. 


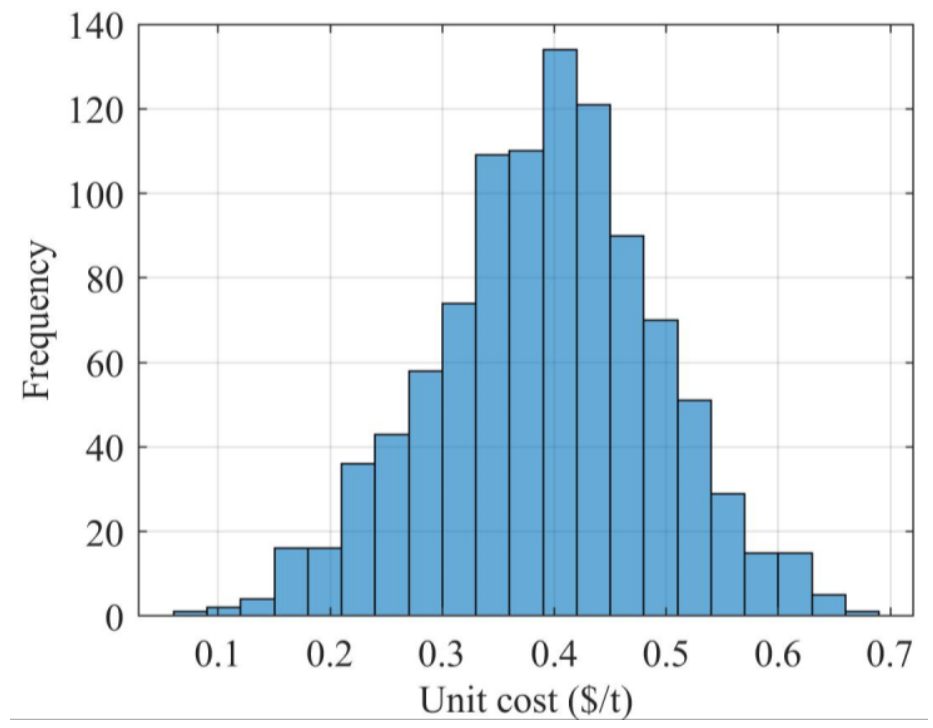

Figure 5. Simulated unit cost of social risk for Alternative 1.

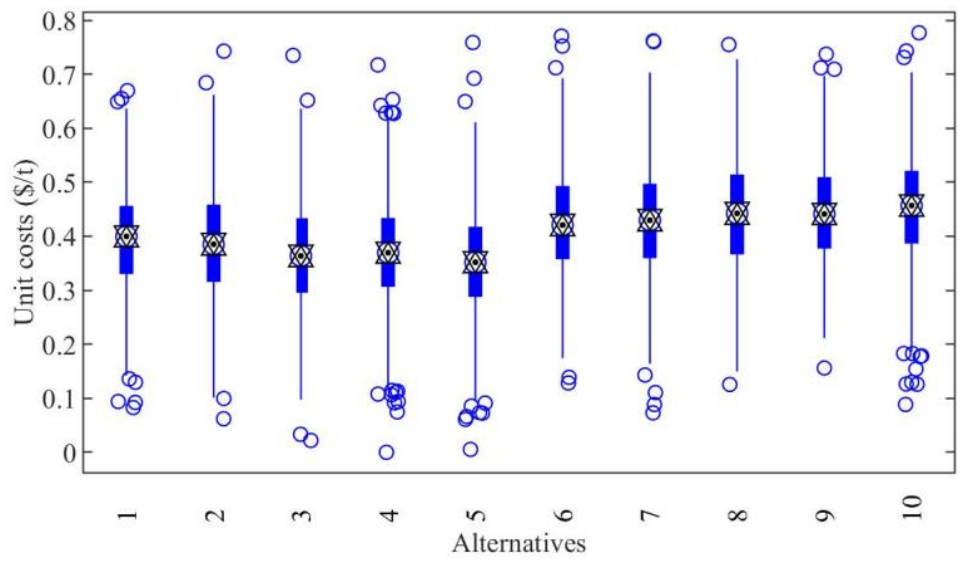

Figure 6. Unit costs of social risk for all alternatives.

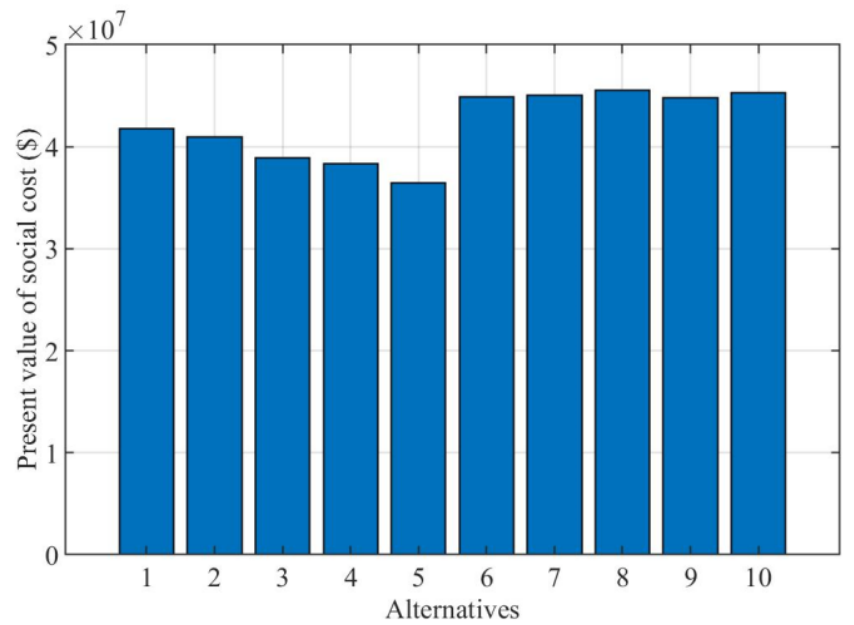

Figure 7. Present value of social risk costs over the mine's life. 
Table 5. Summary of case study results.

\begin{tabular}{cccc}
\hline Alternative & $\begin{array}{c}\text { Social Risk Costs } \\
\text { (\$million) }\end{array}$ & NPV (\$million) & $\begin{array}{c}\text { NPV without Social } \\
\text { Risk Cost (\$million) }\end{array}$ \\
\hline 1 & $\$ 42$ & $\$ 3.651$ & $\$ 3.692$ \\
2 & $\$ 41$ & $\$ 3.757$ & $\$ 3.798$ \\
3 & $\$ 39$ & $\$ 3.723$ & $\$ 3.762$ \\
4 & $\$ 38$ & $\$ 3.973$ & $\$ 4.012$ \\
5 & $\$ 36$ & $\$ 4.056$ & $\$ 4.092$ \\
6 & $\$ 45$ & $\$ 3.553$ & $\$ 3.598$ \\
7 & $\$ 45$ & $\$ 3.745$ & $\$ 3.790$ \\
8 & $\$ 46$ & $\$ 3.896$ & $\$ 3.942$ \\
9 & $\$ 45$ & $\$ 4.142$ & $\$ 4.187$ \\
10 & $\$ 45$ & $\$ 4.256$ & $\$ 4.301$ \\
\hline
\end{tabular}

\subsection{Discussion}

Based on the case study results in Table 5, Alternative 10 is the optimal alternative as it has the highest expected NPV (utility) of $\$ 4.256$ billion. While this happens to also be the alternative with the highest NPV without accounting for community acceptance and attendant social risk costs, the benefit of using the approach proposed here is still clear. The decision-based design framework we propose here explicitly accounts for the community acceptance and adjusts management's expectation of value ( $\$ 4.256$ instead of $\$ 4.301$ billion). Moreover, in cases where the cost of social risks is high, relative to the overall NPV, it can be a determining factor in evaluating alternatives. In this case study, however, the magnitude of the social risk cost is not large enough to change the outcome of this analysis. It is important to note, though, that this is not always going to be the case.

The social risk cost, in this case, is affected more by employment opportunities associated with the alternatives than by mine life. Figure 8 shows the relationship between the social risk cost and employment opportunities. The observed relationship is consistent with the discrete choice model we used in our case study. Table 4 shows the coefficients of the conditional logit model for job opportunities (number of people to be employed) and mine life are 1.1259 and 0.1181 , respectively. It is an interesting observation because, mine life affects the present value of the social risk cost beyond its influence on the unit cost of social risk (through its influence on the community acceptance). The mine life affects the number of years the project incurs social risk cost in estimating the present value of the cost. Nevertheless, in this case, the employment opportunities significantly affect the overall social risk cost and should drive design decisions.

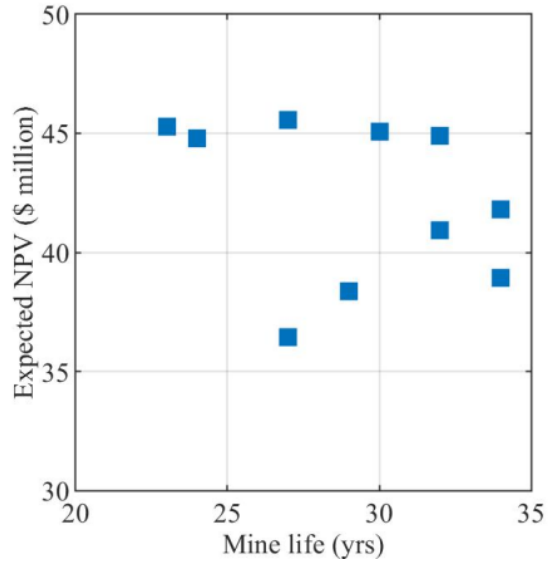

(a)

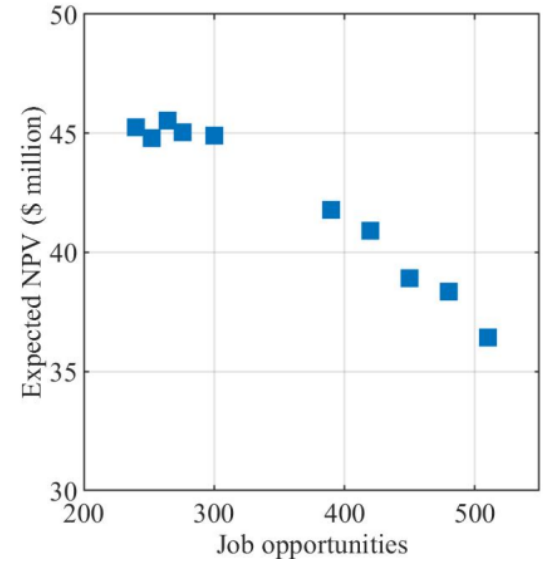

(b)

Figure 8. Effect of mine life and job opportunities on social risk cost: (a) effect of mine life; (b) job opportunities. 
Overall, the case study illustrates that we can successfully incorporate community acceptance and the associated social risks cost into long range mine planning and design using decision-based design and discrete choice theory. As we mentioned earlier, there are only limited examples of work that explicitly incorporates sustainability factors into mine planning and design beyond adding the cost of environmental remediation into the cost estimate. For example, Adibi and colleagues [5] incorporated a list of "sustainability indicators" into the ultimate pit limits optimization process for open pit planning using multi-attribute decision making tools. Their approach, however, relies on quantitative multi-criteria decision making, which as others have noted, often masks the subjective decisions inherent in accounting for qualitative criteria [19,20]. Our proposed framework explicitly accounted for community acceptance and its associated social risk costs, which is normally an externality, using decision-based design and discrete choice theory. By proposing a means to estimate the cost accruing from a lack of community support with attributes of the design alternatives, we avoid the use of subjective weights to evaluate the importance of community attributes in the design. This is the key contribution of this work.

We recognize that, while tools that help engineers quantify the nature and costs of risks arising from interactions with stakeholders can be helpful in gaining the attention of decision makers inside companies, these tools alone cannot ensure community acceptance. Therefore, using the tools proposed in this paper, by themselves, do not ensure that host communities will accept the optimal mine plan generated by engineers. The use of this and similar tools will only be successful if they are combined with a genuine effort to create shared value and effective community engagement to understand the concerns and desires of community members and other stakeholders. If the design objectives are jointly formulated (or at least formulated with input from stakeholders), then designs that drive towards those objectives are much more likely to receive acceptance from the community members.

We believe further research can incorporate other sustainability factors into the framework proposed by this work to make for a more comprehensive evaluation. For example, with the push towards low carbon mining, one could incorporate the cost associated with carbon emissions into this framework easily. Other factors such as the impact of the mine on ecological attributes and the ecological services they provide to the community can also be incorporated if cost functions are developed explicitly to account for the associated costs and benefits associated with mine planning and design alternatives. There is basis in the literature for assigning value to ecosystem services provided by nature [37] that are promising for this type of work. Future work should attempt to incorporate these into the framework proposed in this work.

\section{Conclusions}

This paper presented a framework based on decision-based design and discrete choice analysis to account for local acceptance in mine planning and design. The framework builds on previous work on decision-based design that uses discrete choice analysis to evaluate customer demand for the design alternatives. The proposed framework uses discrete choice analysis to estimate the probability that the community will accept each design alternative. Using a cost function that relates the level of community acceptance (probability of community members choosing that alternative) to social risk cost, this framework incorporates community acceptance as a cost term in estimating the expected net present value, which is the utility for the design decision.

The work uses the mine strategic mine planning exercise of a gold mine as a case study to illustrate this framework. For the specific case study, Alternative 10 is the optimal alternative with an NPV of $\$ 4.256$ billion after accounting for social risk cost over the life of the project that amounts to $\$ 45$ million in present value terms. The work finds that the social risk cost is more sensitive to the job opportunities associated with the alternatives than the mine life. The case study shows that the proposed framework is viable and can adequately incorporate community acceptance. This framework can be a useful tool for 
designing mines for sustainability, if combined with effective community engagement and management's desire to create shared value.

Future work should extend this framework to include other sustainability factors such as carbon footprint and ecosystem services impacted by mining. The basic framework of decision-based design and discrete choice analysis can be extended to incorporate these terms if functions can be developed to incorporate these items as costs or revenues.

Author Contributions: Conceptualization, K.A.-O. and S.Q.; methodology, K.A.-O. and A.U.R.; data curation, K.A.-O. and A.U.R.; writing—original draft preparation, K.A.-O.; writing—review and editing, S.Q. and A.U.R.; funding acquisition, K.A.-O. All authors have read and agreed to the published version of the manuscript.

Funding: This research was funded by Union Pacific/Rocky Mountain Energy Professor in Mining Engineering Endowment at Missouri University of Science \& Technology.

Institutional Review Board Statement: Not applicable.

Informed Consent Statement: Not applicable.

Data Availability Statement: Not applicable.

Acknowledgments: We are grateful for the comments of the reviewers that improved this paper by refining our definition of social risk and better articulating the conditions under which the proposed tool will be successful.

Conflicts of Interest: The authors declare no conflict of interest.

\section{Appendix A. Case Study Mine Planning Results}

Table A1. Results of Whittle mine scheduling optimization of case study results; total production (ore and waste) per period in millions of tonnes.

\begin{tabular}{|c|c|c|c|c|c|c|c|c|c|c|}
\hline \multirow[t]{2}{*}{ Year } & \multicolumn{10}{|c|}{ Alternatives } \\
\hline & 1 & 2 & 3 & 4 & 5 & 6 & 7 & 8 & 9 & 10 \\
\hline 1 & 6.252 & 6.698 & 8.017 & 7.590 & 8.036 & 6.698 & 7.367 & 8.036 & 9.224 & 9.975 \\
\hline 2 & 9.433 & 10.155 & 10.868 & 11.599 & 12.324 & 10.155 & 11.238 & 12.324 & 14.074 & 15.037 \\
\hline 3 & 11.867 & 12.622 & 13.591 & 14.400 & 15.200 & 12.622 & 14.000 & 15.200 & 17.200 & 18.400 \\
\hline 4 & 15.000 & 16.000 & 15.000 & 18.000 & 18.501 & 16.000 & 17.500 & 18.501 & 18.903 & 21.022 \\
\hline 5 & 13.282 & 13.565 & 14.225 & 16.635 & 18.397 & 13.565 & 15.616 & 18.397 & 21.208 & 22.857 \\
\hline 6 & 14.422 & 15.999 & 14.966 & 17.983 & 19.000 & 15.999 & 17.479 & 19.000 & 21.500 & 23.000 \\
\hline 7 & 14.987 & 16.000 & 15.000 & 18.000 & 19.000 & 16.000 & 17.500 & 19.000 & 21.500 & 23.000 \\
\hline 8 & 15.000 & 16.000 & 15.000 & 18.000 & 19.000 & 16.000 & 17.500 & 19.000 & 21.500 & 23.000 \\
\hline 9 & 15.000 & 16.000 & 15.000 & 18.000 & 19.000 & 16.000 & 17.500 & 19.000 & 21.500 & 23.000 \\
\hline 10 & 15.000 & 16.000 & 15.000 & 18.000 & 19.000 & 16.000 & 17.500 & 19.000 & 21.500 & 23.000 \\
\hline 11 & 15.000 & 16.000 & 15.000 & 18.000 & 19.000 & 16.000 & 17.500 & 19.000 & 21.500 & 23.000 \\
\hline 12 & 15.000 & 16.000 & 15.000 & 18.000 & 19.000 & 16.000 & 17.500 & 19.000 & 21.500 & 23.000 \\
\hline 13 & 15.000 & 16.000 & 15.000 & 18.000 & 19.000 & 16.000 & 17.500 & 19.000 & 21.500 & 23.000 \\
\hline 14 & 15.000 & 16.000 & 15.000 & 18.000 & 19.000 & 16.000 & 17.500 & 19.000 & 21.500 & 23.000 \\
\hline 15 & 15.000 & 16.000 & 15.000 & 18.000 & 19.000 & 16.000 & 17.500 & 19.000 & 21.500 & 23.000 \\
\hline 16 & 15.000 & 16.000 & 15.000 & 18.000 & 19.000 & 16.000 & 17.500 & 19.000 & 21.500 & 23.000 \\
\hline 17 & 15.000 & 16.000 & 15.000 & 18.000 & 19.000 & 16.000 & 17.500 & 19.000 & 21.500 & 23.000 \\
\hline 18 & 15.000 & 16.000 & 15.000 & 18.000 & 19.000 & 16.000 & 17.500 & 19.000 & 21.500 & 23.000 \\
\hline 19 & 15.000 & 16.000 & 15.000 & 18.000 & 19.000 & 16.000 & 17.500 & 19.000 & 21.500 & 23.000 \\
\hline 20 & 15.000 & 16.000 & 15.000 & 18.000 & 19.000 & 16.000 & 17.500 & 19.000 & 21.500 & 23.000 \\
\hline 21 & 15.000 & 16.000 & 15.000 & 18.000 & 19.000 & 16.000 & 17.500 & 19.000 & 21.500 & 23.000 \\
\hline 22 & 15.000 & 16.000 & 15.000 & 18.000 & 19.000 & 16.000 & 17.500 & 19.000 & 21.500 & 23.000 \\
\hline 23 & 15.000 & 16.000 & 15.000 & 18.000 & 19.000 & 16.000 & 17.500 & 19.000 & 21.500 & 9.497 \\
\hline 24 & 15.000 & 16.000 & 15.000 & 18.000 & 19.000 & 16.000 & 17.500 & 19.000 & 20.179 & 0.000 \\
\hline 25 & 15.000 & 16.000 & 15.000 & 18.000 & 19.000 & 16.000 & 17.500 & 19.000 & 0.000 & 0.000 \\
\hline 26 & 15.000 & 16.000 & 15.000 & 18.000 & 19.000 & 16.000 & 17.500 & 19.000 & 0.000 & 0.000 \\
\hline
\end{tabular}


Table A1. Cont.

\begin{tabular}{ccccccccccc}
\hline Year & \multicolumn{10}{c}{ Alternatives } \\
\hline & $\mathbf{1}$ & $\mathbf{2}$ & $\mathbf{3}$ & $\mathbf{4}$ & $\mathbf{5}$ & $\mathbf{6}$ & $\mathbf{7}$ & $\mathbf{8}$ & $\mathbf{9}$ & $\mathbf{1 0}$ \\
\hline 27 & 15.000 & 16.000 & 15.000 & 18.000 & 16.330 & 16.000 & 17.500 & 16.330 & 0.000 & 0.000 \\
28 & 15.000 & 16.000 & 15.000 & 18.000 & 0.000 & 16.000 & 17.500 & 0.000 & 0.000 & 0.000 \\
29 & 15.000 & 16.000 & 15.000 & 5.580 & 0.000 & 16.000 & 17.500 & 0.000 & 0.000 & 0.000 \\
30 & 15.000 & 16.000 & 15.000 & 0.000 & 0.000 & 16.000 & 2.088 & 0.000 & 0.000 & 0.000 \\
31 & 15.000 & 16.000 & 15.000 & 0.000 & 0.000 & 16.000 & 0.000 & 0.000 & 0.000 & 0.000 \\
32 & 15.000 & 12.749 & 15.000 & 0.000 & 0.000 & 12.749 & 0.000 & 0.000 & 0.000 & 0.000 \\
33 & 15.000 & 0.000 & 15.000 & 0.000 & 0.000 & 0.000 & 0.000 & 0.000 & 0.000 & 0.000 \\
34 & 12.545 & 0.000 & 6.121 & 0.000 & 0.000 & 0.000 & 0.000 & 0.000 & 0.000 & 0.000 \\
\hline
\end{tabular}

\section{References}

1. Kear, R.M. Strategic and tactical mine planning components. J. S. Afr. Inst. Min. Metall. 2006, 106, 93-96.

2. Quaddus, M.A.; Mukherjee, K. Hierarchical framework for evaluating mine projects for sustainability: A case study from India. In Handbook of Sustainable Development Planning: Studies in Modelling and Decision Support; Edward Elgar Publishing: Cheltenham, UK, 2004; pp. 115-131. ISBN 9781845423544.

3. Newman, A.M.; Rubio, E.; Caro, R.; Weintraub, A.; Eurek, K. A review of operations research in mine planning. Interfaces 2010, 40, 222-245. [CrossRef]

4. Zhang, M.; Zhang, J.; Jiang, F.; Jiao, Z. Design of rib pillars in deep longwall mines based on rockburst and water-seepage prevention. Energy Sci. Eng. 2021, 9, 256-266. [CrossRef]

5. Adibi, N.; Ataee-pour, M.; Rahmanpour, M. Integration of sustainable development concepts in open pit mine design. J. Clean. Prod. 2015, 108, 1037-1049. [CrossRef]

6. Maremi, A.; Ben-Awuah, E.; Askari-Nasab, H. Multi-objective Mathematical Programming Framework for Integrated Oil Sands Mine Planning and Tailings Disposal Optimization. Min. Metall. Explor. 2021, 38, 1355-1374. [CrossRef]

7. Badiozamani, M.M.; Askari-Nasab, H. Integration of reclamation and tailings management in oil sands surface mine planning. Environ. Model. Softw. 2014, 51, 45-58. [CrossRef]

8. Barclay, M.; Franks, D.; Pattenden, C. Risk Communication: A Framework for Technology Development and Implementation in the Mining and Minerals Processing Industries; The Parker Centre \& CSRM: Brisbane, Australia, 1 October 2009; pp. 1-86.

9. Kemp, D.; Worden, S.; Owen, J.R. Differentiated social risk: Rebound dynamics and sustainability performance in mining. Resour. Policy 2016, 50, 19-26. [CrossRef]

10. World Bank Group. The Growing Role of Minerals and Metals for a Low Carbon Future; World Bank: Washington, DC, USA, 2017.

11. Rocha, C.S.; Antunes, P.; Partidário, P. Design for sustainability models: A multiperspective review. J. Clean. Prod. 2019, 234, 1428-1445. [CrossRef]

12. Owen, J.R.; Kemp, D. 'Free prior and informed consent', social complexity and the mining industry: Establishing a knowledge base. Resour. Policy 2014, 41, 91-100. [CrossRef]

13. MacInnes, A.; Colchester, M.; Whitmore, A. Free, prior and informed consent: How to rectify the devastating consequences of harmful mining for indigenous peoples'. Perspect. Ecol. Conserv. 2017, 15, 152-160. [CrossRef]

14. Mahanty, S.; McDermott, C.L. How does "Free, Prior and Informed Consent" (FPIC) impact social equity? Lessons from mining and forestry and their implications for REDD+. Land Use Policy 2013, 35, 406-416. [CrossRef]

15. Thomson, I.; Boutilier, R.G. Social license to operate. In SME Mining Engineering Handbook; Darling, P., Ed.; Society for Mining, Metallurgy, and Exploration, Inc.: Denver, CO, USA, 2011; pp. 1779-1796.

16. Gehman, J.; Lefsrud, L.M.; Fast, S. Social license to operate: Legitimacy by another name? Can. Public Adm. 2017, 60, 293-317. [CrossRef]

17. Zhou, M.; Govindan, K.; Xie, X.; Yan, L. How to drive green innovation in China's mining enterprises? Under the perspective of environmental legitimacy and green absorptive capacity. Resour. Policy 2021, 72. [CrossRef]

18. Taarup-Esbensen, J. Communities as a risk in mining: Managing community legitimacy. J. Risk Res. 2020, 23, 811-826. [CrossRef]

19. Distefano, M.J.; Krubiner, C.B. Beyond the numbers: A critique of quantitative multi-criteria decision analysis. Int. J. Technol. Assess. Health Care 2020, 36, 292-296. [CrossRef] [PubMed]

20. Baltussen, R.; Marsh, K.; Thokala, P.; Diaby, V.; Castro, H.; Cleemput, I.; Garau, M.; Iskrov, G.; Olyaeemanesh, A.; Mirelman, A.; et al. Multicriteria Decision Analysis to Support Health Technology Assessment Agencies: Benefits, Limitations, and the Way Forward. Value Health 2019, 22, 1283-1288. [CrossRef] [PubMed]

21. Hazelrigg, G.A. A framework for decision-based engineering design. J. Mech. Des. Trans. ASME 1998, 120, 653-658. [CrossRef]

22. Wassenaar, H.J.; Chen, W.; Cheng, J.; Sudjianto, A. Enhancing Discrete Choice Demand Modeling for Decision-Based Design. J. Mech. Des. 2005, 127, 514. [CrossRef]

23. Ming, Z.; Sharma, G.; Allen, J.K.; Mistree, F. An Ontology for Representing Knowledge of Decision Interactions in Decision-Based Design. Comput. Ind. 2020, 114, 103145. [CrossRef] 
24. Klotz, L.; Weber, E.; Johnson, E.; Shealy, T.; Hernandez, M.; Gordon, B. Beyond rationality in engineering design for sustainability. Nat. Sustain. 2018, 1, 225-233. [CrossRef]

25. Huang, Z.; Zhao, H.; Zhu, D. Two new prediction-driven approaches to discrete choice prediction. ACM Trans. Manag. Inf. Syst. 2012, 3. [CrossRef]

26. Chen, W.; Hoyle, C.; Wassenaar, H.J. Decision-Based Design: Integrating Consumer Preferences into Engineering Design; Springer Science \& Business Media: Berlin, Germany, 2013; ISBN 9781447140368.

27. McFadden, D. Conditional logit analysis of qualitative choice behavior. Front. Econ. 1974, 1, 105-142. [CrossRef]

28. Ivanova, G.; Rolfe, J. Assessing development options in mining communities using stated preference techniques. Resour. Policy 2011, 36, 255-264. [CrossRef]

29. Que, S.; Awuah-Offei, K.; Wang, L.; Samaranayake, V.A.; Weidner, N.; Yuan, S. Individual preferences for mineral resource development: Perspectives from an urban population in the United States. J. Clean. Prod. 2018. [CrossRef]

30. Que, S.; Wang, L.; Awuah-Offei, K.; Yang, W.; Jiang, H. Corporate social responsibility: Understanding the mining stakeholder with a case study. Sustainability 2019, 11, 2407. [CrossRef]

31. Que, S.; Awuah-Offei, K.; Weidner, N.; Wang, Y. Discrete choice experiment validation: A resource project case study. J. Choice Model. 2017. [CrossRef]

32. Que, S.; Awuah-Offei, K.; Demirel, A.; Wang, L.; Demirel, N.; Chen, Y. Comparative study of factors affecting public acceptance of mining projects: Evidence from USA, China and Turkey. J. Clean. Prod. 2019, 237. [CrossRef]

33. Train, K. Discrete Choice Methods with Simulation; Cambridge University Press: Cambridge, UK, 2002.

34. Petkova, V.; Lockie, S.; Rolfe, J.; Ivanova, G. Mining developments and social impacts on communities: Bowen basin case studies. Rural Soc. 2009, 19, 211-228. [CrossRef]

35. Davis, R.; Franks, D.M. The costs of conflict with local communities in the extractive industry. In Proceedings of the First International Seminar on Social Responsibility in Mininig, Santiago, Chile, 21 October 2011; pp. 1-13.

36. Hochbaum, D.S. The Pseudoflow Algorithm: A New Algorithm for the Maximum-Flow Problem. Oper. Res. 2008, 56, 992-1009. [CrossRef]

37. Nuppenau, E.-A. Eco-system services in Agrarian Value Chains: Value detection of bio-diversity as public good provision, problems, and institutional issues. Sustainability 2018, 11, 26. [CrossRef] 